\title{
Partisan pandemic: How partisanship and public health concerns affect individuals' social mobility during COVID-19
}

\author{
J. Clinton ${ }^{1 *}$, J. Cohen ${ }^{2}$, J. Lapinski ${ }^{3}$ and M. Trussler ${ }^{4}$

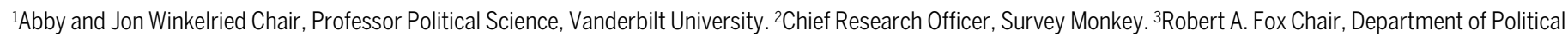 \\ Science, University of Pennsylvania. ${ }^{4}$ Director of Data Science, Penn Program on Opinion Research and Election Studies, University of Pennsylvania.
}

*Corresponding author. Email: josh.clinton@vanderbilt.edu

Rampant partisanship in the United States may be the largest obstacle to the reduced social mobility most experts see as critical to limiting the spread of the COVID-19 pandemic. Analyzing a total of just over 1.1 million responses collected daily between April $4^{\text {th }}$ and September $10^{\text {th }}$ reveals not only that partisanship is more important than public health concerns for explaining individuals' willingness to stay-at-home and reduce social mobility, but also that the effect of partisanship has grown over time - especially among Republicans. All else equal, the relative importance of partisanship for the increasing (un)willingness of Republicans to stay-at-home highlights the challenge that politics poses for public health.

\section{Introduction}

Public health professionals universally agree that preventing the further spread of the COVID-19 pandemic requires a collective public response $(1,2)$. Given the increasing level of partisan polarization in the United States (3), the fact that COVID-19 initially impacted Democratic-leaning urban areas more than Republican-leaning rural areas, and differences in how Republican and Democratic political leaders discuss the pandemic, it is unclear whether the pandemic's threat to public health can overcome partisan differences in the perceived severity of the pandemic and the collective need to reduce social mobility to minimize its' impact. Because the effectiveness of guidelines designed to limit mobility and social contact requires widespread compliance to effectively limit the spread of COVID-19, how much do partisan differences affect concerns about COIVD-19 and the willingness to reduce mobility?

Decades of research in political science has shown that partisan affiliation is not merely a description of where individuals stand on the ideological spectrum (4), but instead a highly stable (5), emotionally laden (3), social identity (6), that describes many of an individual's social groupings and deeply held values (7). An individual's partisan identity affects the information they collect, process, and respond to (811), and the actions they take (12) - including how and whether they choose to receive health care (13-15). However, research on how partisanship influences behavior has never had to reckon with the possibility of these attitudes affecting behavior during a global pandemic which presents a credible threat to the health of individuals and their families.

We examine the importance of partisan considerations relative to public health concerns arising from the incidence of COVID-19 in local communities on the willingness of individuals to social distance to help limit the spread of COVID-19.

Using daily data on the reported activities of 1,135,638 U.S. adults collected starting on April 4, 2020, we show that partisanship is 27 times more important than the local incidence of COVID-19 in explaining mobility. Moreover, all else equal, Democrats are 13.1 percent less likely to be socially mobile over time compared to independents, while Republicans are 27.8 percent more likely to be mobile. These differences have tremendous consequences for the ability of the United States to limit the spread of COVID-19 and they show the importance of politics and political considerations for public health, even during a global pandemic. These results add to a growing consensus that partisanship is a key factor in explaining behavior and attitudes surrounding the COVID-19 pandemic (16-19).

\section{Results}

Two comparisons are of primary interest: 1) how much of the variation in mobility behavior can be attributable to partisanship relative to the impact of COVID-19 in the local community, and 2) the conditional effect of partisanship and COVID19 community cases on mobility.

To begin, Fig. 1 summarizes the patterns in the weighted data over time to demonstrate how these two considerations relate to COVID-19 concerns and social mobility. The top row of plots (A, B) graph the percentage of respondents who report being "very worried" or "somewhat" worried about catching COVID-19 each day between February 11, 2020 and September 29, 2020 using 1,364,012 interviews. The bottom row (Fig. 1C-1D) plots the average number of activities individuals report doing in the last 24 hours using the $1,135,638$ interviews conducted starting on April 4, 2020. The columns 
in Fig. 1 report the daily averages by partisanship (Fig. 1A, 1C) and the quintile of population adjusted COVID-19 cases in the respondents' county (Fig. 1B, 1D), as measured in the first week of May. Figures S13 and S14 reproduce these relationships for age groups and Census regions - neither show differences in mobility and concern that are equal to those generated by partisanship.

Several results immediately emerge from the raw data. First, although Democrats are more concerned with catching COIVD-19 than Republicans throughout, the concerns of both were increasing until early April when Republicans became increasingly less concerned while Democrats maintained their level of concern. Suggestively, this increasing partisan divide accelerates the same week President Trump tweeted about the need to "liberate" Michigan, Minnesota, and Virginia (April 17). By early June, only approximately $40 \%$ of Republicans report being concerned compared to around $80 \%$ of Democrats. Republicans' concerns increased as the pandemic worsened through June and into July, but a large partisan gap persists.

Figure 1B demonstrates that these differences are not due to differences in the incidence of COVID-19 in the respondents' communities. The average level of concern does not greatly vary depending on whether a respondent lives in one of most or least impacted counties (measured in the first week of May).

The impact of these concerns for mobility is equally clear. When the mobility questions were originally asked in early April there were few partisan differences - reflecting that Democrats and Republicans were taking similar steps to stay at home. Over time, however, plot C (Fig. 1C) shows that although all respondents report engaging in more social activities over time on average, the increase is greatest among Republicans. Republicans increase the number of social activities by 1.24 on average (a $75 \%$ increase). This is in comparison to the 0.86 increase (60\% increase) among pure independents, and significantly higher than the 0.63 increase (47\% increase) among Democrats. Considering the average number of social activities by COVID-19 impact in the local community (Fig. 1D) reveals relatively less social activity in the most impacted counties, but the differences between the most and least impacted counties is considerably less than the differences between Democrats and Republicans.

To better decompose the impact of partisanship and COVID-19 on the willingness of individuals to social distance we estimate several daily regression models to estimate the conditional effect of each on mobility as well as how much variation in mobility is explained by each. We regress the level of self-reported activity in the last 24 hours for individual $i$ in state $j$ on state fixed-effects $\left(\alpha_{\mathrm{j}}\right)$ (to control for between-state differences) and a matrix of individual-level and zip-code level demographics $\left(\boldsymbol{K}_{i}\right)$ to account for other possible sources of variation. Demographic covariates are gender, age, race, education, income, population density, and employment status. We then estimate models that iteratively add party indicators (with pure independents as the excluded category) and the change in COVID-19 deaths in the individual's county in the previous week. The four models we estimate for each day $t$ are:

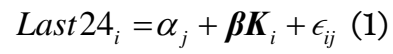

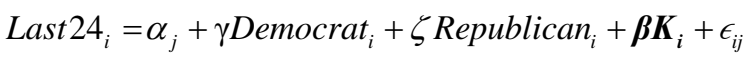

$$
\begin{aligned}
& {\text { Last } 24_{i}=\alpha_{j}+\eta \text { County.Change.in.COVID.Cases }}_{i}+\boldsymbol{\beta} \boldsymbol{K}_{i}+\epsilon i_{j}
\end{aligned}
$$

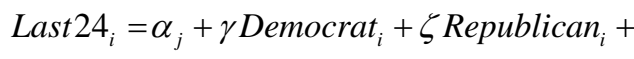

$$
\begin{aligned}
& \eta \text { County.Change.in.COVID.Cases }{ }_{i}+\boldsymbol{\beta} \boldsymbol{K}_{i}+\epsilon_{i j}
\end{aligned}
$$

The first result of interest is provided by the coefficients of partial determination for partisanship and the change in COVID-19 cases in the respondent's county. The coefficient of partial determination is determined by dividing the difference in the residual sum of squares between the demographic and fuller models by the residual sum of squares in the demographic model. It determines how much of the variation left unexplained by demographics and state fixed-effects to characterize how much of the residual variation in Eq. 1 is explained by adding partisanship (Eq. 2) or COVID-19 cases (Eq. 3), and summarizes the extent to which variation in mobility can be explained by partisanship and public health considerations. The conditional marginal effects of partisanship and COVID-19 cases on mobility are provided by a regression including both partisanship and COVID-19 considerations (Eq. 4).

Figure 2 reports percentage of residual variation in social mobility that is explained by partisanship and the local incidence of COVID-19 over time. In early April, neither partisanship nor public health concerns explain a large amount of the residual variation in mobility - primarily because there was little variation to explain given that most individuals were drastically reducing their social behaviors. Over time, partisan variation explains an increasing percentage of variation in mobility; around $7 \%$ of the variation in mobility that is not explained by demographics or state is explained by the party affiliation of the respondent in May. As the pandemic begins to re-strengthen in late June, however, the predictive power of partisanship recedes to a (still robust) $5 \%$, before rising again throughout August to its previous level. Throughout the series public health, in contrast, consistently explains only a small amount of this residual variation.

To determine how partisanship and local COVID-19 cases are predicted to impact individuals' mobility, Fig. 3 graphs 
the marginal effect of partisanship (with independent as the base category) and change in COVID-19 deaths over time from specification (4). Whereas Fig. 1C presents the weighted daily averages in the raw data, Fig. 3 graphs the marginal effect of each consideration in a model using statistical controls to allow for all-else-equal comparisons.

The results are striking. The blue line in Fig. 3 reveals that Democrats are less likely to engage in social activities than independents and they are increasingly likely to so do over time. By early June, Democrats are engaging in -0.31 less activities than independents all else equal. In contrast, Republicans (red line) are increasingly more likely to engage in social activities than independents such that they are engaging in more than 0.6 social activities than pure independents on average in June (red line). Altogether, Republicans are therefore engaging in 0.93 additional social activities on average than Democrats in early June. Moreover, the increasing effect of partisanship on mobility is asymmetric: all else equal, Republicans are increasing their social activity far more than other Americans are changing their behavior. Notably, as the pandemic surged in June the effect of partisanship began to recede, but this regression was small and temporary. Through July and August large partisan differences began to expand once again.

While partisanship matters greatly for mobility, the impact of the population adjusted change in COVID-19 cases in a respondent's county (green line) only has small negative effect of behavior. As expected, there is a slight decrease in social activity for individuals living in counties with large number of cases relative to other counties in their states. But recall in Fig. 2 that this variable only explains a miniscule proportion of variance in mobility.

Our statistical controls rule out the most plausible alternative hypotheses for differences that might be related to age, race, education, income, gender, employment status, or population density. The differences we identify also cannot be explained by Republicans living in states where social activity is more permissible (whether de jure or de facto) because the effects being identified are based on within-state differences given the state fixed effects we employ. Tables S1 \& S2 show the robustness of these results using pooled models that examine within-state and within-Zip-Code variation over time.

While our main effects cannot be explained by different proportions of partisans living in states with more-or-less stringent lockdown regulations, it may still be the case that the within-state relationship between party and social activity differs from state to state. In particular, there may be a complex interaction between the party of a state's governor, the COVID Mitigation policies put in place, and the degree to which partisanship is associated with different levels of social activity. That Democrats are less socially active may be driven, for example, by Democrats living in Democratic led states with more stringent lock-down policies (e.g., New York) being cued by locally trusted leaders that activity should be limited; alternatively, the same relationship may be driven by Republicans in those same Democratic led states actively flaunting the regulations put in place by a local leader to whom they feel a great deal of antipathy.

Figure 4 visualizes these possibilities, displaying the marginal conditional effect of being a Democrat or Republican (versus an Independent) separately for each state. States with Democratic governors are displayed in panel A, and states with Republican Governors in Panel B. On the horizontal axis we sort the states by the aggressiveness of their COVID-19 mitigation policies, determined by the length of the state stay-at-home order, whether the state has a mask mandate, whether the state has travel restrictions in place, the testing capacity of the state, and the contact tracing capacity of the state. These different components were standardized and then scaled together using Principal Components Analysis. (See SM S8).

Figure 4 makes clear that there is a remarkable degree of stability in the size of the coefficients within party and across states. In states run by both Republican and Democratic governors' Republican citizens are significantly more active than Independents. Similarly, Democrats in all states are significantly less active than Independents. It is not the case that the main relationship described above is driven, for example, by Republicans in Democratic states with aggressive COVID mitigation policies flaunting the law; or, alternatively, Democrats in Republican led states with less aggressive COVID mitigation policies staying home more. Instead, Democrats and Republicans across the country have remarkably similar levels of activity to like-partisans in other states (relative to Independents).

These results largely conform to previous research which finds an increasingly nationalized politics in the United States (20-22). One hypothesis for this more nationalized response to politics is an increasingly nationalized media system. We investigate this further in the Supplementary Material, and find that the relationship between partisanship and mobility in our data are heightened for those who consume a great deal of news (Figure S16), and that Republican's lower level of concern over the virus is associated with their viewership of right-wing news sources like Fox News (Figure S17).

\section{Discussion}

Our results point to an unequivocal conclusion: partisanship is a far more important determinant of an individual's response to the COVID-19 pandemic than the impact of COVID19 in that individual's local community. The implications of this are significant. The COVID-19 pandemic in the United States is currently as much a political problem as it is a public 
health problem. Given the differences in perceptions and behavior we document between Democrats and Republicans exposed to the same level of COVID-19 in their local communities, simply highlighting the public health concerns associated with COVID-19 seems unlikely to encourage the collective decline in social mobility that is required to help mitigate the further spread of the pandemic. Instead, political leadership - especially by Republicans - seems essential for changing the partisan-related differences we document in individuals' behaviors and opinion.

While our analyses do not identify the source for the partisan differences we identify, they do rule out some important plausible explanations. In particular, the fact that partisan differences we identify persist regardless of the partisanship of the governor, differences in the regulatory environment of the state, regional differences, local differences (at the zip code level) and media consumption suggests that they are due to either national stimuli (e.g., cues being provided by national partisan leaders such as President Trump and/or partisan-related differences in the beliefs and values of partisans. In either case, it is clear that national leadership seems required to help bridge the partisan differences we identify.

\section{Materials and Methods}

Analyzing how partisanship affects mobility requires individual level data to avoid issues related to ecological inference that may be present when looking at relationships in aggregate units such as counties (23), particularly because Democrats are more likely to live in more population dense places (24) that have been more heavily impacted by COVID-19 to date (25). To track the relationship between partisanship, the incidence of COVID-19 in local communities, and social activity we interview 1,135,638 randomly selected respondents from the Survey Monkey platform between April 4, 2020 and September 7, 2020 (26). Every day, an average of 6744 respondents were interviewed and weighted to be representative of the US adult population using the most current estimates from the U.S. Census Bureau's American Community Survey. Weighting ensures that the daily estimates are not only nationally representative, but also directly comparable over time $(27,28)$.

Our primary outcome measure is whether respondents report going to a restaurant, visiting family or friends, taking a walk, exercising, getting groceries, receiving medical care, and going to work in the last 24 hours. We focus on an additive count of the number of activities an individual reports, but Fig S4 and S5 show that similar results are obtained when analyzing voluntary activities (e.g., going to a restaurant) and involuntary activities (e.g., seeking medical care) separately. Figure S5 reveals that the partisan gap in the activities thought most "risky" - going to restaurants and visiting friends and families - are larger than those for "safer" activities.
Relying on any self-report raises concerns about the truthfulness in responses. We feel that a measure which focuses on the last 24 hours is the best solution to mitigate this risk. Focusing on personal activity occurring in the last 24 hours places lower cognitive demand on respondents and it focuses the respondent to think about personal behavior rather than public policy (which may be affected by aspirational political considerations). Asking about support for "stay-at-home" measures in general, for example, are more likely to result in responses based on partisan messaging about the severity of the COVID-19 pandemic. Asking about personal behavior in the last 24 hours trades-of an increase in variance (because behavior in the 24 hours may not be representative of their behavior in general) in the hopes of reducing such bias. Our approach is consistent with leading contemporary measures of media exposure that also only ask about the previous 24 hours of activity (29).

To validate our measure, Fig. S3 compares our self-reported mobility index to anonymized cell phone data from Google measuring the change in how long individuals are at various locations (30). The national average of our 24-hour activity measure reassuringly correlates quite strongly (0.91) with Google's measure of change in mobility around retail and recreation.

Our key explanatory variables are the self-reported partisanship of each respondent, and the severity of COVID-19 in their local community. To measure partisanship, we rely on the branching question that is standard in the literature (31). Respondents are first asked whether they identify with the Republican or Democratic Party. Those who identify with neither, are asked whether they "lean" closer to either of the two parties. Only individuals who do not lean are classified as "independent" because "leaners" are known to behave similar to self-identifying partisans $(32,33)$. Table S1 confirms that the behavior of leaners and partisans are largely indistinguishable when it comes to social activity.

To measure the impact of COVID-19 in each respondent's community we use the Johns Hopkins Center for Systems Science and Engineering COVID-19 database to calculate the change in COVID-19 cases per 1000 residents in each respondent's county in the week prior to their interview. ${ }^{1}$ Because these numbers have been widely reported, they arguably describe and define respondents' lived experiences with COVID-19 in their community. Figures S6-S12 show our conclusions are robust to using alternative measures: change in county deaths $/ 1000$, absolute county cases $/ 1000$, absolute county deaths $/ 1000$, change in state cases/1000, change in state deaths $/ 1000$, absolute state cases/1000, and absolute state deaths/1000. ${ }^{2}$ Table S3 displays pooled results for our 4 main specifications using Change in State Cases/1000 as the measure of COVID-19 incidence. The coefficient of partial determination for specification 3 is slightly higher using this 
alternative measure - explaining $0.26 \%$ of the variance in specification 1 compared to $0.22 \%$ for the county-level version of this variable. Overall, while the state-level measure explains slightly more variation, it is still swamped by the effect of party, which explains 23 times more variation.

\section{REFERENCES AND NOTES}

1. Center for Disease Control, Social Distancing, Quarantine, and Isolation, (available at https:/www.cdc.gov/coronavirus/2019-ncov/prevent-getting-sick/socialdistancing.html).

2. World Health Organization, Advice for public, (available at https://www.who.int/emergencies/diseases/novel-coronavirus-2019/advicefor-public).

3. S. Iyengar, S. J. Westwood, Fear and Loathing across Party Lines: New Evidence on Group Polarization. Am. J. Pol. Sci. (2015). doi:10.1111/ajps.12152

4. A. Campbell, P. E. Converse, W. E. Miller, D. E. Stokes, The American Voter (University of Chicago Press, 1960).

5. P. E. Converse, The nature of belief systems in mass publics (1964). Crit. Rev. 18 1-74 (2006). doi:10.1080/08913810608443650

6. D. P. Green, B. Palmquist, E. Schickler, Partisan hearts and minds: Political parties and the social identities of voters (Yale University Press, 2004).

7. L. Mason, Uncivil agreement: How politics became our identity (University of Chicago Press, 2018).

8. J. R. Zaller, The nature and origins of mass opinion (Cambridge university press, 1992).

9. G. S. Lenz, Follow the leader?: how voters respond to politicians' policies and performance (University of Chicago Press, 2013).

10. M. Levendusky, How partisan media polarize America (University of Chicago Press, 2013).

11. C. H. Achen, L. M. Bartels, Democracy for realists: Why elections do not produce responsive government (Princeton University Press, 2017), vol. 4.

12. M. F. Margolis, M. W. Sances, Partisan differences in nonpartisan activity: The case of charitable giving. Polit. Behav. 39, 839-864 (2017). doi:10.1007/s11109$\underline{016-9382-4}$

13. M. A. Baum, Red state, blue state, flu state: Media self-selection and partisan gaps in Swine flu vaccinations. J. Health Polit. Policy Law 36, 1021-1059 (2011). $\underline{\text { doi:10.1215/03616878-1460569 Medline }}$

14. A. E. Lerman, M. L. Sadin, S. Trachtman, Policy uptake as political behavior: Evidence from the Affordable Care Act. Am. Polit. Sci. Rev. 111, 755-770 (2017). doi:10.1017/S0003055417000272

15. M. W. Sances, J. D. Clinton, Who participated in the ACA? Gains in insurance coverage by political partisanship. J. Health Polit. Policy Law 44, 349-379 (2019). doi:10.1215/03616878-7366988

16. J. D. Clinton, J. S. Lapinski, S. Lentz, S. Pettigrew, Trumped by Trump? Public Support for Vote By Mail Voting in Response to the COVID-19 Pandemic. Available SSRN (2020), doi:https://dx.doi.org/10.2139/ssrn.3630334.

17. S. Kushner Gadarian, S. W. Goodman, T. B. Pepinsky, Partisanship, Health Behavior, and Policy Attitudes in the Early Stages of the COVID-19 Pandemic. Available SSRN (2020), doi:https://dx.doi.org/10.2139/ssrn.3562796.

18. C. Makridis, J. T. Rothwell, The Real Cost of Political Polarization: Evidence from the COVID-19 Pandemic. Available SSRN (2020), doi:https://www.ssrn.com/abstract=3638373.
19. D. G. Young, A. Bleakley, Ideological Health Spirals: An Integrated Political and Health Communication Approach to COVID Interventions. Int. J. Commun. 14, 1$17(2020)$

20. D. J. Hopkins, The increasingly United States: How and why American political behavior nationalized (University of Chicago Press, 2018).

21. G. C. Jacobson, It's nothing personal: The decline of the incumbency advantage in Us House Elections. J. Polit. 77, 861-873 (2015). doi:10.1086/681670

22. M. Trussler, Get Information or Get in Formation: The Effects of High-Information Environments on Legislative Elections. Br. J. Polit. Sci. 1-21 (2020). doi:10.1017/S0007123419000577

23. S. Piantadosi, D. P. Byar, S. B. Green, The ecological fallacy. Am. J. Epidemiol. 127, 893-904 (1988). doi:10.1093/oxfordjournals.aje.a114892 Medline

24. J. G. Gimpel, N. Lovin, B. Moy, A. Reeves, The Urban-Rural Gulf in American Political Behavior. Polit. Behav. 42, 1343-1368 (2020). doi:10.1007/s11109-02009601-w

25. Center for Disease Control, S. Bialek, V. Bowen, N. Chow, A. Curns, R. Gierke, A. Hall, M. Hughes, T. Pilishvili, M. Ritchey, K. Roguski, B. Silk, T. Skoff, P. Sundararaman, E. Ussery, M. Vasser, H. Whitham, J. Wen, “Geographic Differences in COVID-19 Cases, Deaths, and Incidence-United States, February 12-April 7, 2020" (2020).

26. Survey Monkey, Survey methodology: How SurveyMonkey gets its data | SurveyMonkey, (available at https://www.surveymonkey.com/mp/surveymethodology/)

27. J. N. Druckman, C. D. Kam, in Cambridge Handbook of Experimental Political Science (2012).

28. J. D. Clinton, A. M. Engelhardt, M. J. Trussler, Knockout blows or the status quo? Momentum in the 2016 primaries. J. Polit. 81, 997-1013 (2019). doi:10.1086/703383

29. S. Dilliplane, S. K. Goldman, D. C. Mutz, Televised Exposure to Politics: New Measures for a Fragmented Media Environment. Am. J. Pol. Sci. (2013). doi:10.1111/i.1540-5907.2012.00600x

30. Google, COVID-19 Community Mobility Reports, (available at https://www.google.com/covid19/mobility/data documentation.html).

31. The American National Election Studies, The ANES Guide to Public Opinion and Electoral Behavior, (available at https://electionstudies.org/resources/anesguide/).

32. B. E. Keith, E. Orr, M. C. Westlye, R. E. Wolfinger, D. B. Magleby, C. J. Nelson, The Partisan Affinities of Independent 'Leaners".'. Br. J. Polit. Sci. 16, 155-185 (1986). doi:10.1017/S0007123400003872

33. S. Klar, Y. Krupnikov, Independent Politics (Canbridge University Press, 2016).

\section{ACKNOWLEDGMENTS}

We are grateful to Jack Chen for assistance in data collection. Funding: The authors acknowledge that they received no funding in support of this research. Author contributions: All authors contributed equally to the design, implementation, and analysis of this project. Competing interests: All authors declare that they have no competing interests. Data and materials availability: The data and code needed to replicate the results can be downloaded here: https://datadryad.org/stash/dataset/doi:10.5061/dryad.3bk3j9khg.

\section{SUPPLEMENTARY MATERIALS}

advances.sciencemag.org/cgi/content/full/sciadv.abd7204/DC1

Submitted 7 July 2020

Accepted d13 November 2020

Published First Release 11 December 2020

10.1126/sciadv.abd7204 

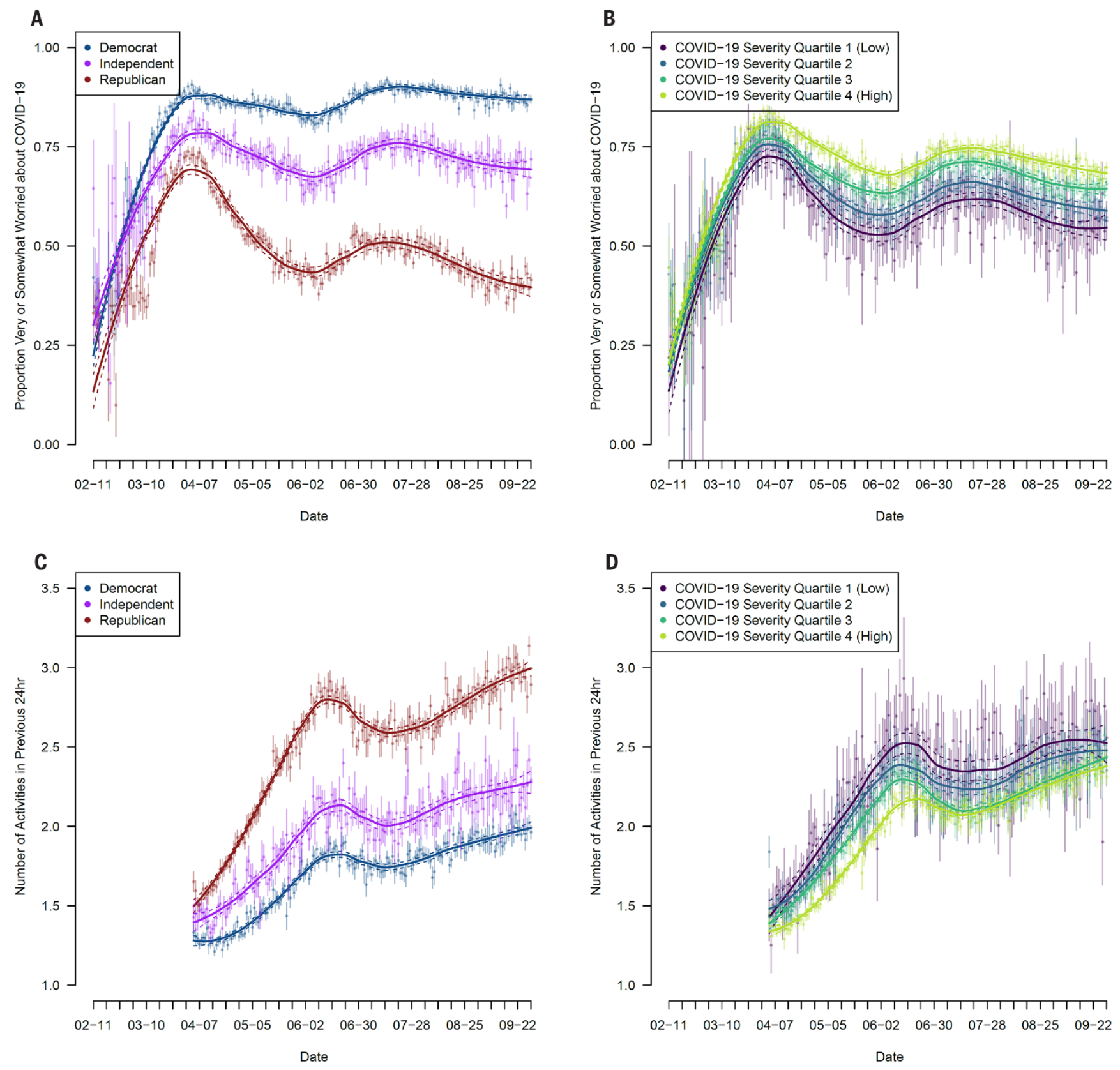

Fig. 1. Concern with Catching COVID-19 and Mobility Over time by Partisanship and COVID-19 Impact in the Community. Plots (A, B) graph the weighted (to the adult US population) daily percentage of respondents who are "very" or "somewhat" worried about catching COVID-19 and Plots (C, D) graph the average number of social activities individuals report doing in the last 24 hours. Plots $(A, C)$ report the daily averages by partisanship and Plots (B, D) report the average for each quintile of population adjusted COVID-19 cases in respondents' counties in the first week of May. 95\% confidence intervals are reported for each daily average and plotted lines are loess smoothers to summarize trends over time. 


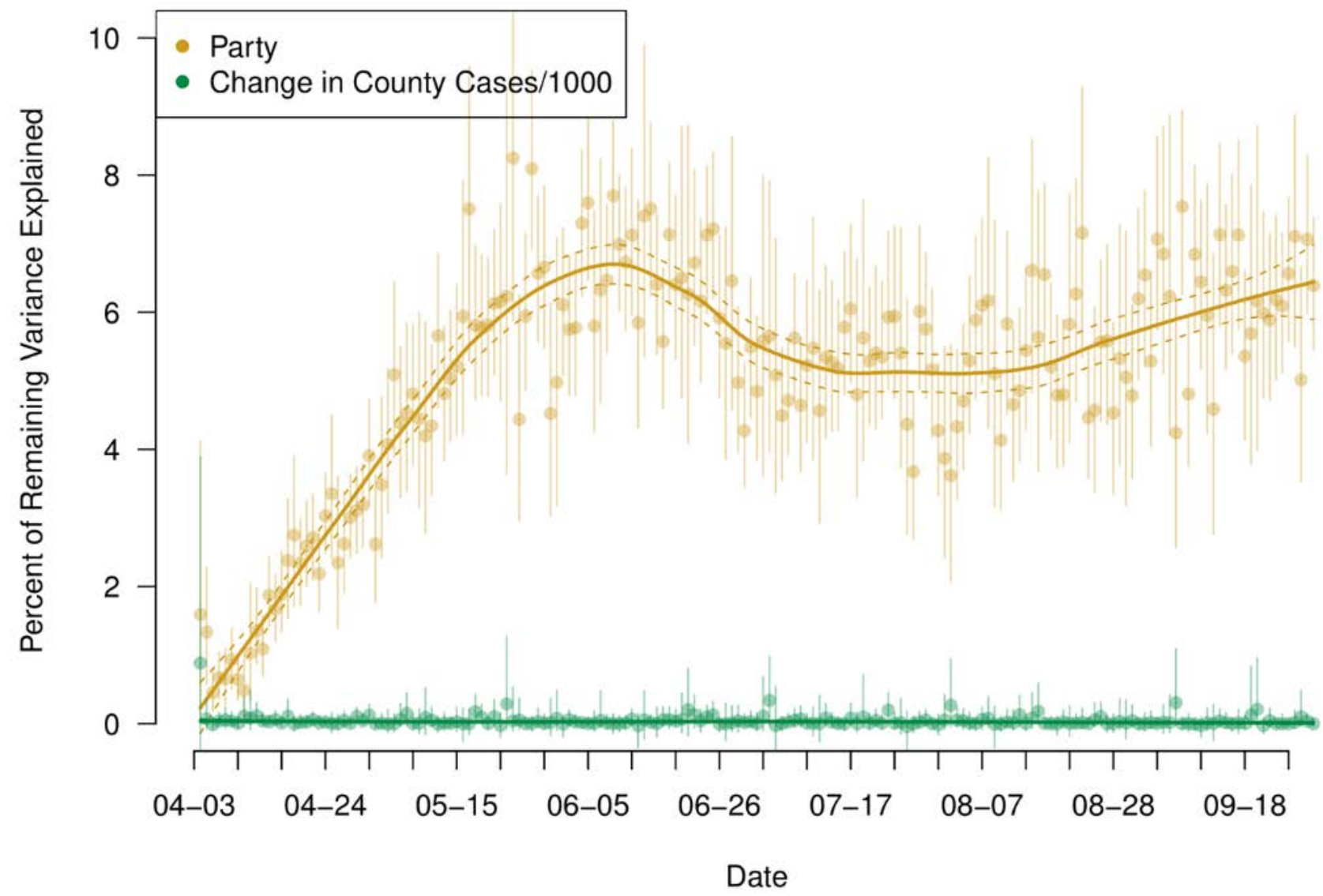

Fig. 2. Variation in Mobility Explained by Partisanship and the Impact of COVID-19 in the Community. The daily coefficients of partial determinations are computed via OLS regression using specifications (13) run separately on each day. Observations weighted to the US adult population. They describe the percent of residual variation in specification (1) that is explained by our two key variables. Standard errors are from 1000 bootstrap samples for each day and represent the 95\% distribution of bootstrap estimates. Trend is local regression weighted by the inverse of each estimate's standard error. 


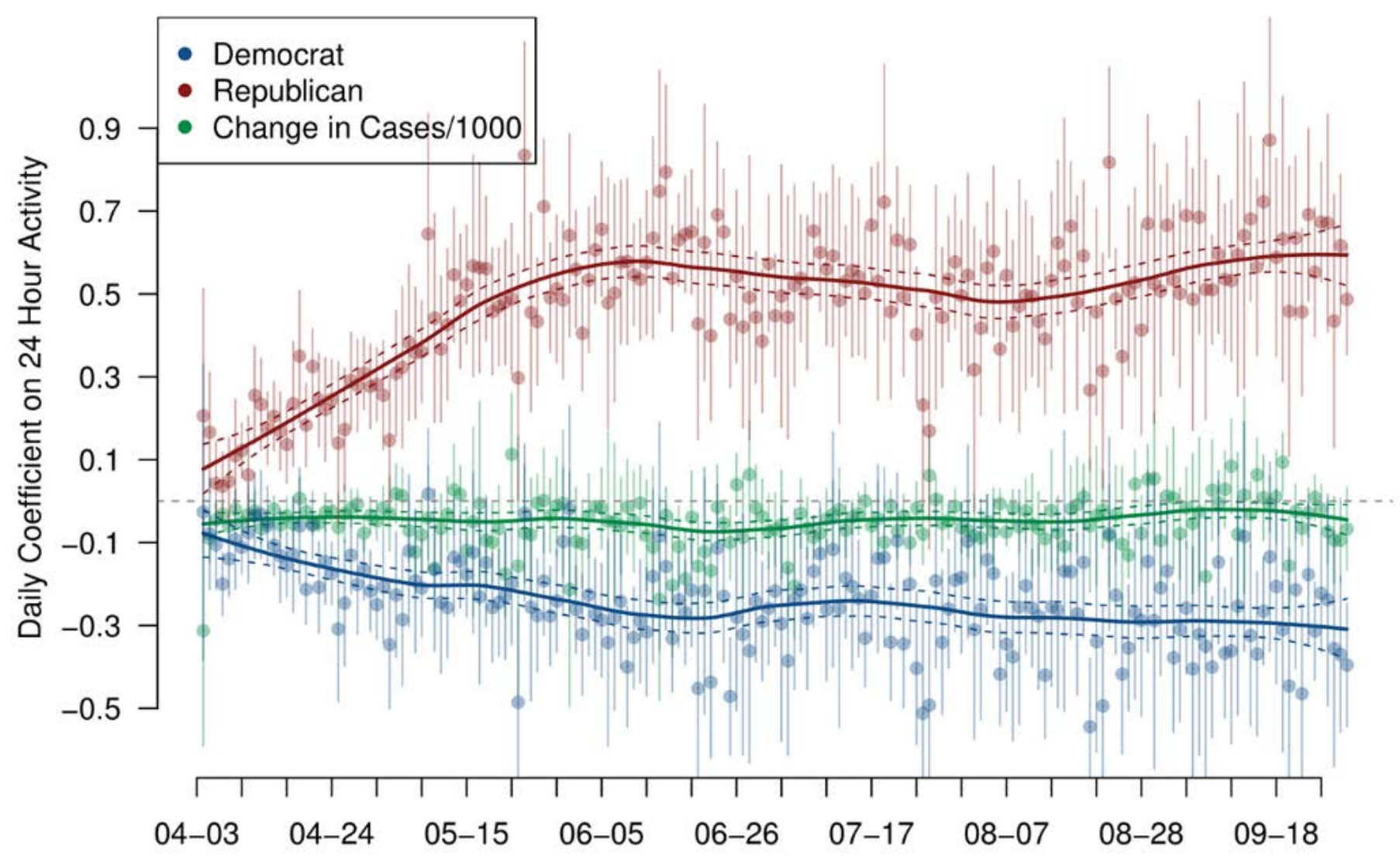

Fig. 3. Marginal Conditional Effect of Partisanship and COVID-19 cases on Mobility over time. Coefficients are from OLS regression using specification (4) run separately on each day. Observations weighted to the US adult population. For party variables, reference is pure independents. Partisan leaners are included with identifying partisans. 95\% confidence intervals from OLS standard errors clustered by state. Trend is local regression weighted by the inverse of each estimate's standard error. 
States with Democratic Governors

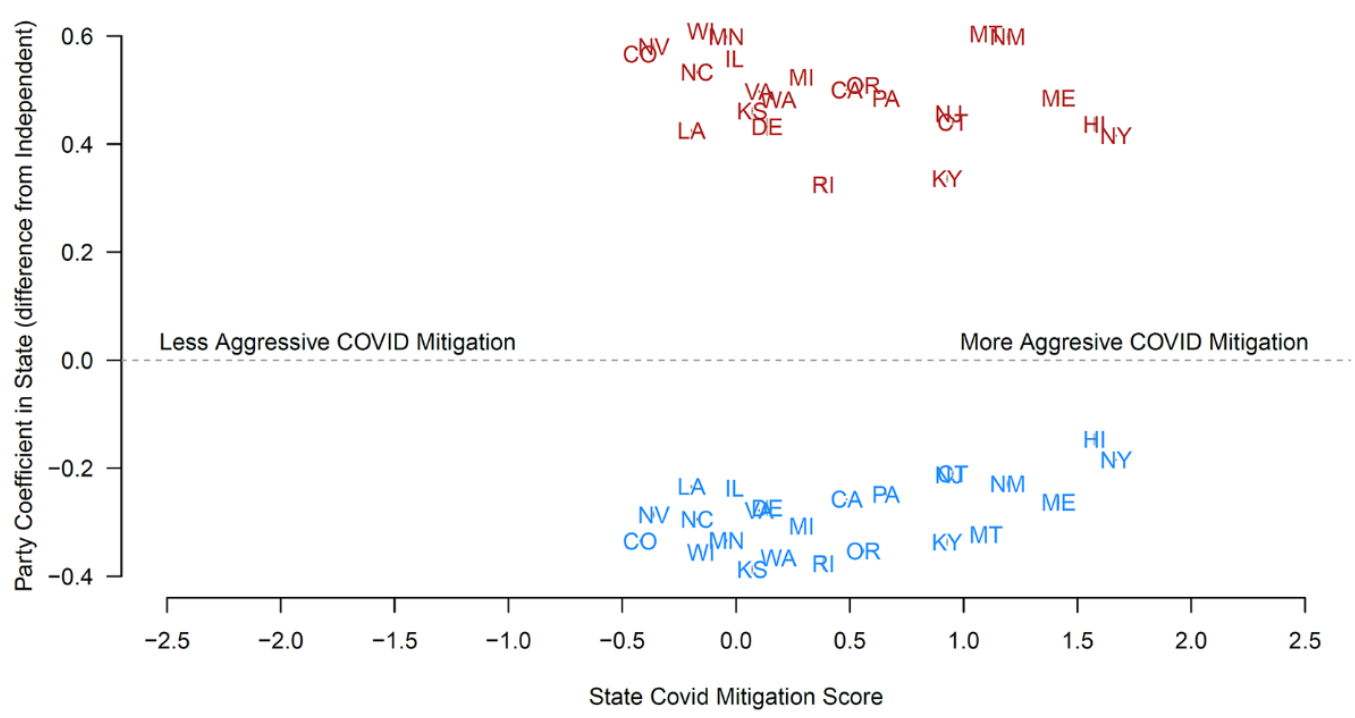

States with Republican Governors

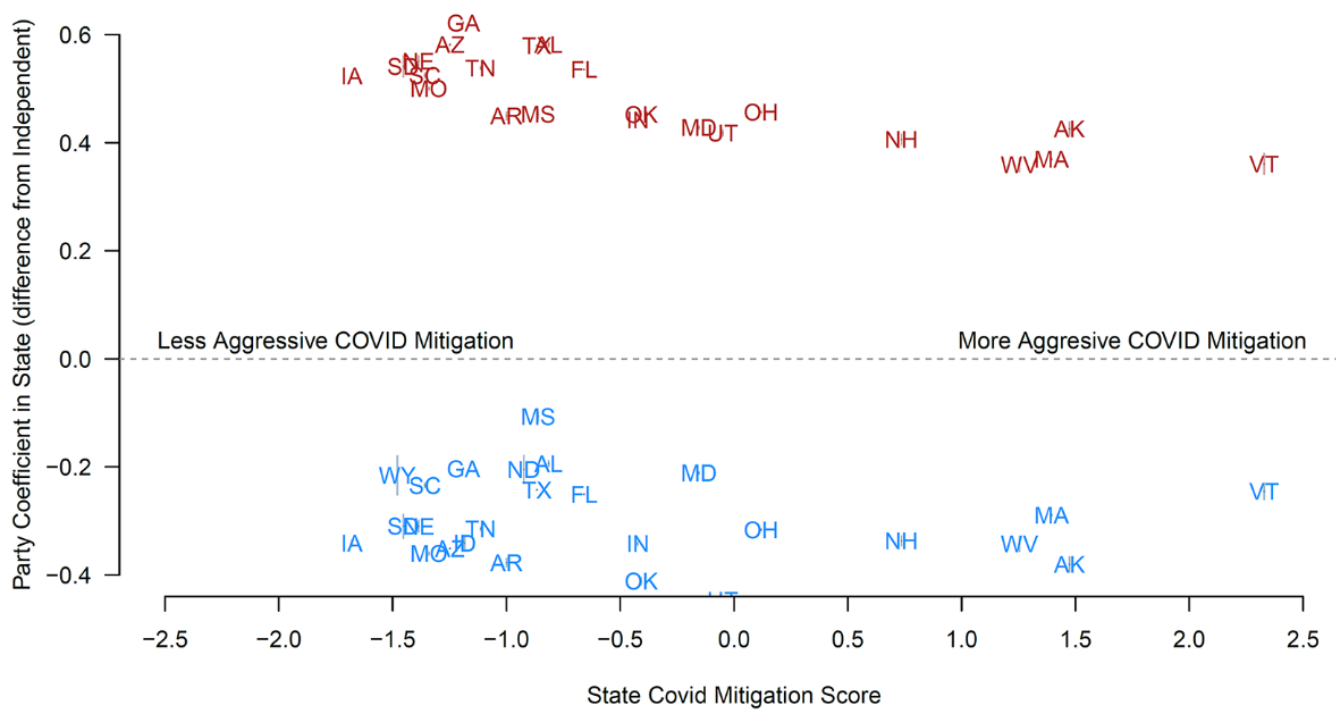

Fig. 4. Marginal Conditional Effects of Partisanship by State. The coefficients and 95\% confidence intervals are from estimating using OLS from a pooled model of same-state respondents using specification (4). Because we pool all respondents from a state over time, a polynomial time trend is used to account for time-varying differences. Coefficients are in relation to pure independents. The separate state results are reported according to the state's aggressiveness of COVID-19 mitigation policies, with higher numbers indicating more aggressive policies to stop the spread. Observations are weighted to the state adult population. 